\title{
Deficiency of terminal complement pathway inhibitor promotes neuronal tau pathology and degeneration in mice
}

\author{
Markus Britschgi $i^{1 *}$, Yoshiko Takeda-Uchimura ${ }^{1}$, Edward Rockenstein ${ }^{2}$, Hudson Johns $^{1}$, Eliezer Masliah ${ }^{2}$ \\ and Tony Wyss-Coray ${ }^{1,3^{*}}$
}

\begin{abstract}
Background: The neuronal microtubule-associated protein tau becomes hyperphosphorylated and forms aggregates in tauopathies but the processes leading to this pathological hallmark are not understood. Because tauopathies are accompanied by neuroinflammation and the complement cascade forms a key innate immune pathway, we asked whether the complement system has a role in the development of tau pathology.
\end{abstract}

Findings: We tested this hypothesis in two mouse models, which expressed either a central inhibitor of complement or lacked an inhibitor of the terminal complement pathway. Complement receptor-related gene/ protein $\mathrm{y}$ is the natural inhibitor of the central complement component C3 in rodents. Expressing a soluble variant (sCrry) reduced the number of phospho-tau (AT8 epitope) positive neurons in the brain stem, cerebellum, cortex, and hippocampus of aged P301L mutant tau/sCrry double-transgenic mice compared with tau single-transgenic littermates (JNPL3 line). CD59a is the major inhibitor of formation of the membrane attack complex in mice. Intrahippocampal injection of adeno-associated virus encoding mutant human P301L tau into Cd59a-/- mice resulted in increased numbers of AT8-positive cells compared with wild-type controls. This was accompanied by neuronal and synaptic loss and reduced dendritic integrity.

Conclusions: Our data in two independent mouse models with genetic changes in key regulators of the complement system support the hypothesis that the terminal pathway has an active role in the development of tau pathology. We propose that inhibition of the terminal pathway may be beneficial in tauopathies.

Keywords: Age-related neurodegeneration, Alzheimer's disease, Complement system, Frontotemporal lobar degeneration, Innate immune system, Mouse models of tau pathology, Tauopathy

\section{Findings}

Intraneuronal insoluble deposits of the microtubuleassociated protein tau are found in neurodegenerative diseases commonly known as tauopathies [1]. One of the causes leading to these deposits in sporadic tauopathies may be aberrant phosphorylation of tau. A common feature in Alzheimer's disease (AD), the most prevalent tauopathy, and other tauopathies is activation of immune pathways in the brain. The complement

\footnotetext{
* Correspondence: markus.britschgi@roche.com; twc@stanford.edu

'Department of Neurology and Neurological Sciences, Stanford University School of Medicine, 1201 Welch Road; MSLS Bldg, Rm P208, Stanford, CA 94305-5489, USA

${ }^{3}$ Center for Tissue Regeneration, Repair and Restoration, Veterans Affairs Palo Alto Health Care System, 3801 Miranda Ave, Palo Alto, CA 94304, USA Full list of author information is available at the end of the article
}

system is a key innate immune pathway, which is fully expressed in the brain, independent of peripheral contribution, and exerts critical homeostatic cerebral functions in development and aging (for extensive discussions and citations of relevant original articles about the role of complement system in the brain see [2,3]). Brains of patients with Pick's disease (a pure tauopathy), AD, or individuals with Down's syndrome with AD-pathology are found to have tangle-bearing neurons that are decorated with complement proteins, including the membrane attack complex (MAC). The presence of MAC in the brain even at early stages of $\mathrm{AD}$ or the deposition of products of complement activation in aged normal brains [4] suggests a lack of proper inhibitory control of the cascade with age and disease. Indeed, in affected 
brain regions of $\mathrm{AD}$ patients, levels of the main inhibitor of the MAC, CD59, are reduced [5,6]. These histological and biochemical findings in human beings open the question whether complement activation and formation of the MAC, in particular, are involved in the development of tau pathology.

To test this hypothesis we crossed human mutant P301L tau transgenic mice (line JNLP3, herein called 'tau transgenic', a model for a genetic form of a pure tauopathy [7]; all described mouse experiments have been approved by the Palo Alto Veterans Hospital Institutional Review Board for Animal Experiments) with transgenic mice overexpressing a soluble form of the murine complement receptor 1-related gene/protein y (sCrry) [8] (Figure 1A). Tau transgenic $(n=13)$ and double-transgenic tau/sCrry mice $(n=17)$ were aged until the first mice started to present with the described lack of hind limb splay or weight loss in this line [7]. The symptoms developed, however, only in very few mice and only after 15 to 20 months, which was much slower and later in life than reported for the original line on a mixed genetic background. Mice were sacrificed and $30 \mu \mathrm{m}$ floating cryotome brain sections were stained according to the mouse-on-mouse protocol (Vector Labs) with the phospho-tau specific antibody AT8 $(0.5 \mu \mathrm{g} / \mathrm{ml}$, mouse monoclonal antibody; Pierce Thermo Scientific). After developing with immunoperoxidase and diaminobenzidine, the number of AT8-positive cell bodies was counted blindly by two independent observers using light microscopy. AT8 immunoreactivity was observed in the neocortex, deep cerebellar nuclei, and, most prominently, brainstem but only in about onethird of all mice (Figure 1B). Despite this lack of consistent penetration of tau pathology, the proportion of mice that developed tau pathology in brainstem was significantly higher in tau transgenic mice (6/13) compared with the complement-inhibited tau/sCrry transgenic mice $(2 / 17)$ (Figure 1C; two-tailed Fisher's exact test $P=0.049$ ). An increased inter-mouse variability of tau pathology has been described previously for the JNLP3 line after crossing it for several generations onto the C57BL/6 background [9]. Here, tau and tau/sCrry

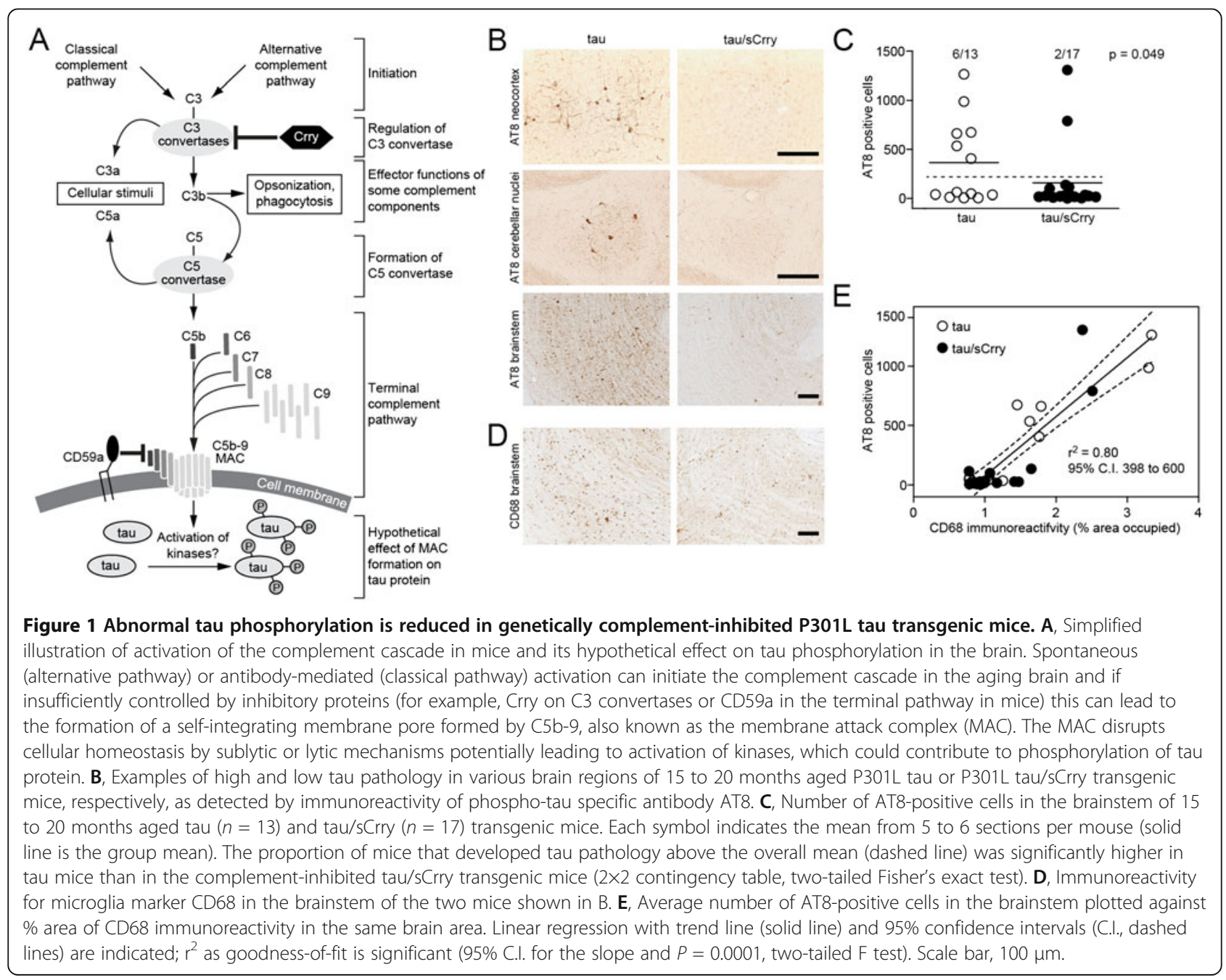


transgenic mice had a mixed background with at least $70 \%$ calculated contribution of the C57BL/6 J background. Neuroinflammation was quantified by relative staining intensity of microglial marker CD68 (diluted 1:50, FA-11; Serotec) in the same brain region. CD68 staining intensity correlated highly with the abundance of AT8-positive cells (Figure 1D,E). Together, this points to an involvement of innate immune pathways and in particular the complement system in tau pathology.

Insertion of the MAC into the cell membrane in mice is tightly controlled by CD59a in mice and in human beings by CD59 [10] (Figure 1A). A lack thereof leaves cells more susceptible to spontaneous and induced attack by the MAC $[10,11]$. To test the effect of CD59adeficiency on tau phosphorylation in the brain, $C d 59 a-/-$ mice $(n=5)$ [11] and wild-type littermates $(n=3)$ aged 4.5 months were injected stereotaxically with an adenoassociated virus (AAV2 serotype) encoding human P301L mutant tau in the right hippocampus and with an AAV2 encoding green fluorescent protein (GFP, internal control) in the left hippocampus. Two microliters of each AAV2 (tau or GFP; $8 \times 10^{12} \mathrm{vg} / \mathrm{ml}$ [12]) were injected with a $10 \mu \mathrm{l}$ Hamilton syringe for $2 \mathrm{~min}$ at a rate of $1 \mu \mathrm{l} / \mathrm{min}$ in a nanoinjector system. The needle was allowed to remain in the brain for an additional $2 \mathrm{~min}$. The coordinates were anterior/posterior from bregma $-2.0 \mathrm{~mm}$, lateral $+/-$ $1.5 \mathrm{~mm}$, and dorsal/ventral $1.4 \mathrm{~mm}$. After 5 months, mice were sacrificed and prepared for histological analysis as described previously. We observed a strong cytoplasmic and neuritic GFP signal in the granular layer of AAV2GFP injected hippocampi of wild-type and Cd59-/- mice, consistent with robust expression of GFP and efficient transduction by AAV2. Occasionally, GFP-positive neurites were also present in the contralateral hemisphere (Figure 2A). The hippocampus of $C d 59 a-/-$ mice expressing human P301L mutant tau had significantly higher levels of AT8-positive cells than the respective hippocampus of their wild-type littermates (Figure 2A,B; $P=0.036$, Mann-Whitney $U$ test). AT8 immunoreactivity was detected in neuronal cell bodies, neurites, and axons in the CA2 and CA3 regions of the tau-injected side (Figure 2A). Relative staining intensity of microglial marker CD68 did not correlate with immunoreactivity for tau phosphorylation (Figure 3A,B). Tau phosphorylation was, however, accompanied by significant reduction of hippocampal immunoreactivity for markers of neuronal (NeuN and microtubule-associated protein 2, MAP-2; both antibodies at 1:500, Millipore) and synaptic integrity (synaptophysin, 1:500, Millipore) (Figure 3C-H; ANOVA and post-hoc Tukey-Kramer test). In conclusion, lack of CD59a promotes abnormal tau phosphorylation and loss of neuronal and synaptic integrity in mouse brains producing human P301L mutant tau pointing to an active role of the terminal complement pathway in tau pathology.

Earlier studies in mouse models of tauopathies reported a strong link between microglia activation and development of tau pathology [13-17] or vice versa [18]. Whereas some identified this link after administration of an exogenous trigger of inflammation [14-16], we observed a significant correlation between microglial activation and the number of AT8-positive cells in tau

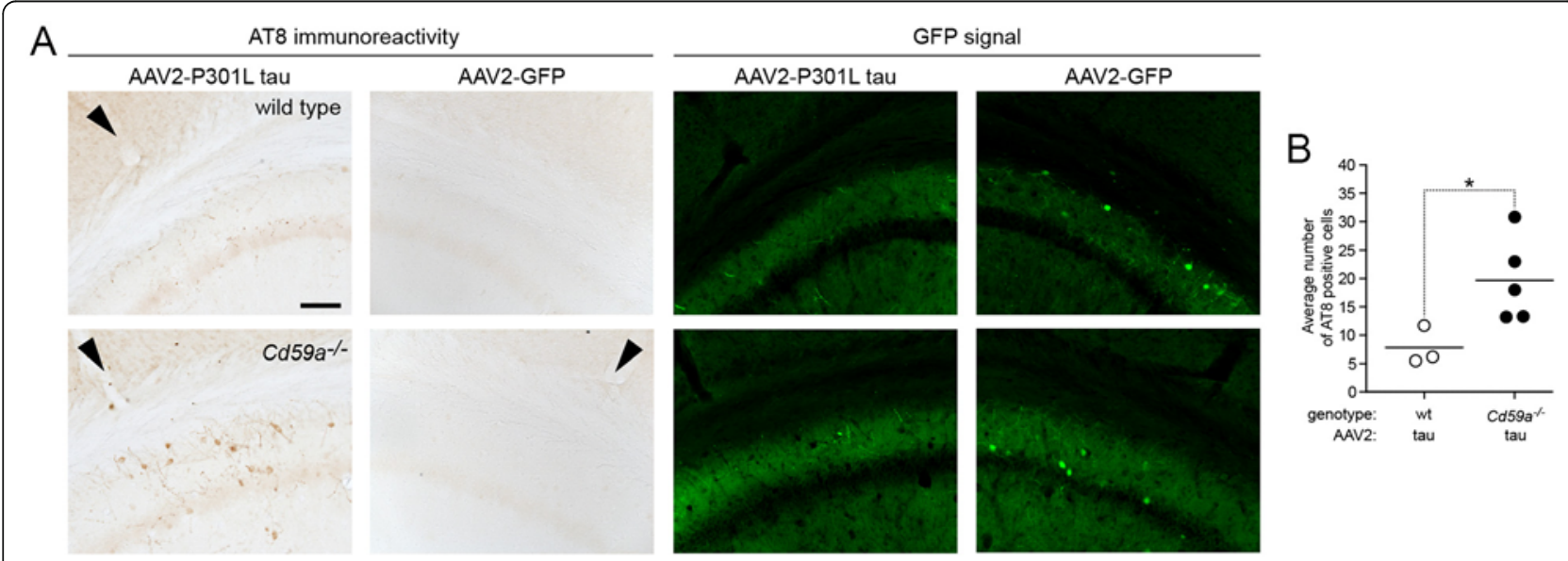

Figure 2 Lack of CD59a promotes abnormal tau phosphorylation, which is accompanied by neuronal and synaptic degeneration. A, Immunoreactivity of AT8 phosphorylated tau in the granular cell layer of the CA2/3 region of Cd59a-/- mice ( $n=5$ ) and wild-type (wt) littermate controls $(n=3) 5$ months after intrahippocampal injection of adeno-associated virus (AAV2) encoding human P301L mutant tau (arrowheads indicates needle track). Contralateral hippocampus was injected with AAV2 encoding green fluorescent protein (AAV2-GFP), resulting in cytoplasmic and neuritic distribution of GFP. Occasionally, GFP-positive neuritis can also be observed in the AAV2-P301L tau-injected hemisphere. B, Number of AT8-positive cell bodies in the entire AAV2-P301L tau-injected hippocampus in Cd59a-/- mice and wild-type littermate controls. Each symbol indicates the mean number of 3 to 4 sections per mouse. Significance was calculated by Mann-Whitney $U$ test; ${ }^{*} P \leq 0.05$. Scale bar, $100 \mu \mathrm{m}$. 


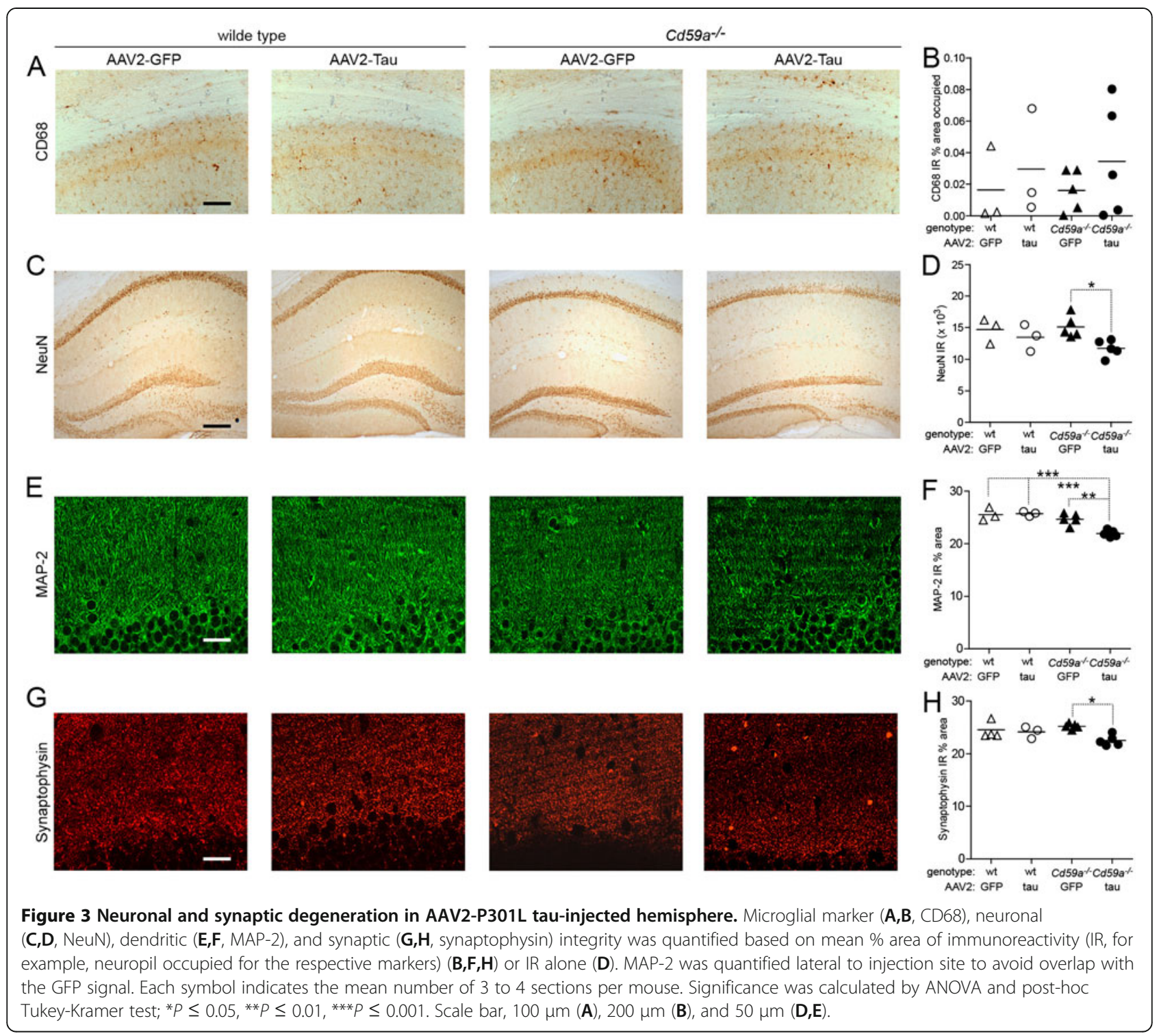

transgenic mice in the absence of exogenous stimuli (Figure 1D,E), which is consistent with findings in the brains of AD patients [19].

A growing number of studies show that the complement system probably has multiple functions in normal and injured brain and this may be relevant for $\mathrm{AD}[2,3]$. For instance, overexpression of sCrry or ablating C3 in APP transgenic mouse models of AD accelerated formation of amyloid- $\beta$ plaques and neurodegeneration $[20,21]$. This apparently protective effector function of the central component of the complement cascade may involve the opsonization of plaques followed by clearance of amyloid (Figure 1A). In contrast, full activation of the complement system and the terminal or lytic pathway can lead to formation of the MAC with possibly detrimental consequences. If not properly controlled by
CD59, the MAC can generate differently sized (lytic and sublytic) pores in the cell membrane. Such pores then lead to increased $\mathrm{Ca}^{2+}$ influx, which may trigger depolarization of the membrane and activation of kinases in the cell [22]. Thus, full complement activation involving the terminal pathway and MAC formation may be upstream in the activation of kinases, such as MAPK, PKC, JNK, or PI3K/AKT, which have been implicated in the regulation of tau phosphorylation. Cellular and in vivo experiments also demonstrate that MAC formation in neurons can induce seizures and excitotoxicity, which promote neurodegeneration [23]. Excitotoxicity and seizures have also been proposed to contribute to cognitive decline in $\mathrm{AD}$ mouse models and patients. Interestingly, the absence of tau protects APP transgenic and wild-type mice from excitotoxic insults and 
prevents behavioral deficits [24]. Whether MAC formation and excitotoxicity are linked through tau would need to be studied in more detail.

Neuropathological analyses in human beings and our in vivo data do indeed point to an active role of the terminal complement pathway in the development of tau pathology, a neuropathological hallmark of $\mathrm{AD}$ and other tauopathies. Intriguingly, recent genome-wide association studies identified independently genetic variants of complement receptor 1 (CR1/CD35) and clusterin to be associated with $\mathrm{AD}$ ([25], replicated by others: www.alzgene.org). CR1/CD35 is one of the human functional analogs of the murine Crry and clusterin, which is also known as apolipoprotein $\mathrm{J}$ or complement lysis inhibitor, acts just one step upstream of CD59. It is interesting that, out of all immune-function-related proteins, two key regulators of the central component and the terminal cascade seem to be genetically linked with $\mathrm{AD}$. It remains to be shown whether variants of genes coding for complement components or regulators are associated with other tauopathies as well.

In summary, complement proteins are key components of the innate immune system and have been implicated in homeostasis as well as degeneration of the human brain. Our data in two independent mouse models with genetic alterations in complement regulatory proteins support the hypothesis that the terminal pathway has an active role in the development of tau pathology. We propose that inhibition of the terminal pathway and, more specifically, inhibition of the MAC may be beneficial in tauopathies.

\section{Abbreviations}

AAV2: Adeno-associated virus serotype 2; AD: Alzheimer's disease; CR1: Complement receptor 1; GFP: Green fluorescent protein; IR: Immunoreactivity; MAC: Membrane attack complex; MAP-2: Microtubuleassociated protein 2; sCrry: Soluble complement receptor 1-related gene/ protein $y$; wt: Wild-type.

\section{Competing interests}

MB is currently a full-time employee of Roche/F. Hoffmann-La Roche Ltd., Basel, Switzerland. The data related to this manuscript were generated when MB was still at Stanford University and the manuscript was written when MB was already at Roche. The authors declare that they have no competing interests.

\section{Authors' contributions}

$M B$ and TW-C designed research and wrote the paper; MB, YT-U, HJ, ER, and EM performed research; MB, EM, and TW-C analyzed data. All authors read and approved the final manuscript

\section{Acknowledgements}

We thank Drs. S. Tomlinson (Medical University of South Carolina, USA) and BP Morgan (Cardiff University School of Medicine, UK) for providing the Cd59a-/- mice, and J Warner and LH Mondshein for technical assistance. This work was supported by the Swiss National Science Foundation (postdoctoral fellowship PBBEB-102096 to MB), NIH (AG18440, AG02074, AG10435 to EM), National Institute on Aging (AG20603 and AG27505 to TW-C), and the Department of Veterans Affairs (TW-C).

\section{Author details}

${ }^{1}$ Department of Neurology and Neurological Sciences, Stanford University School of Medicine, 1201 Welch Road; MSLS Bldg, Rm P208, Stanford, CA 94305-5489, USA. ²Departments of Neurosciences and Pathology, University of California San Diego, 9500 Gilman Drive \# 9127, La Jolla, CA 92093-9127, USA. ${ }^{3}$ Center for Tissue Regeneration, Repair and Restoration, Veterans Affairs Palo Alto Health Care System, 3801 Miranda Ave, Palo Alto, CA 94304, USA.

Received: 3 May 2012 Accepted: 8 September 2012

Published: 18 September 2012

\section{References}

1. Lee VM, Goedert M, Trojanowski JQ: Neurodegenerative tauopathies. Annu Rev Neurosci 2001, 24:1121-1159.

2. Stephan AH, Barres BA, Stevens B: The complement system: an unexpected role in synaptic pruning during development and disease. Annu Rev Neurosci 2012, 35:369-389.

3. Veerhuis R, Nielsen HM, Tenner AJ: Complement in the brain. Mol Immunol 2011, 48(14):1592-1603.

4. Loeffler DA, Camp DM, Schonberger MB, Singer DJ, LeWitt PA: Early complement activation increases in the brain in some aged normal subjects. Neurobiol Aging 2004, 25(8):1001-1007.

5. Yasojima K, McGeer EG, McGeer PL: Complement regulators C1 inhibitor and CD59 do not significantly inhibit complement activation in Alzheimer disease. Brain Res 1999, 833(2):297-301.

6. Yang LB, Li R, Meri S, Rogers J, Shen Y: Deficiency of complement defense protein CD59 may contribute to neurodegeneration in Alzheimer's disease. J Neurosci 2000, 20(20):7505-7509.

7. Lewis J, McGowan E, Rockwood J, Melrose H, Nacharaju P, Van Slegtenhorst M, Gwinn-Hardy K, Murphy MP, Baker M, Yu X, Duff K, Hardy J, Corral A, Lin W-L, Yen S-H, Dickson D, Davies P, Hutton M: Neurofibrillary tangles, amyotrophy and progressive motor disturbance in mice expressing mutant (P301L) tau protein. Nat Genet 2000, 25(4):402-405.

8. Quigg RJ, He C, Lim A, Berthiaume D, Alexander JJ, Kraus D, Holers VM: Transgenic mice overexpressing the complement inhibitor Crry as a soluble protein are protected from antibody-induced glomerular injury. J Exp Med 1998, 188:1321-1331.

9. Bolmont T, Clavaguera F, Meyer-Luehmann M, Herzig MC, Radde R, Staufenbiel M, Lewis J, Hutton M, Tolnay M, Jucker M: Induction of tau pathology by intracerebral infusion of amyloid- $\beta$-containing brain extract and by amyloid- $\beta$ deposition in APP $x$ Tau transgenic mice. Am J Pathol 2007, 171(6):2012-2020.

10. Baalasubramanian S, Harris CL, Donev RM, Mizuno M, Omidvar N, Song WC, Morgan BP: CD59a is the primary regulator of membrane attack complex assembly in the mouse. J Immunol 2004, 173(6):3684-3692.

11. Holt DS, Botto M, Bygrave AE, Hanna SM, Walport MJ, Morgan BP: Targeted deletion of the CD59 gene causes spontaneous intravascular hemolysis and hemoglobinuria. Blood 2001, 98(2):442-449.

12. Ubhi K, Rockenstein E, Doppler E, Mante M, Adame A, Patrick C, Trejo M, Crews L, Paulino A, Moessler H, Masliah E: Neurofibrillary and neurodegenerative pathology in APP-transgenic mice injected with AAV2-mutant TAU: neuroprotective effects of Cerebrolysin. Acta Neuropathol (Berl) 2009, 117(6):699-712.

13. Jaworski $T$, Lechat $B$, Demedts $D$, Gielis L, Devijver $H$, Borghgraef $P$, Duime $H$, Verheyen F, Kugler S, Van Leuven F: Dendritic degeneration, neurovascular defects, and inflammation precede neuronal loss in a mouse model for tau-mediated neurodegeneration. Am J Pathol 2011 179(4):2001-2015.

14. Bhaskar K, Konerth M, Kokiko-Cochran ON, Cardona A, Ransohoff RM, Lamb BT: Regulation of tau pathology by the microglial fractalkine receptor. Neuron 2010, 68(1):19-31.

15. Kitazawa M, Oddo S, Yamasaki TR, Green KN, LaFerla FM: Lipopolysaccharide-induced inflammation exacerbates tau pathology by a cyclin-dependent kinase 5-mediated pathway in a transgenic model of Alzheimer's disease. J Neurosci 2005, 25(39):8843-8853.

16. Li Y, Liu L, Barger SW, Griffin WS: Interleukin-1 mediates pathological effects of microglia on tau phosphorylation and on synaptophysin synthesis in cortical neurons through a p38-MAPK pathway. J Neurosci 2003, 23(5):1605-1611.

17. Yoshiyama Y, Higuchi M, Zhang B, Huang SM, Iwata N, Saido TC, Maeda J, Suhara T, Trojanowski JQ, Lee VM: Synapse loss and microglial activation 
precede tangles in a P301S tauopathy mouse model. Neuron 2007, 53(3):337-351.

18. Zilka N, Stozicka Z, Kovac A, Pilipcinec E, Bugos O, Novak M: Human misfolded truncated tau protein promotes activation of microglia and leukocyte infiltration in the transgenic rat model of tauopathy. J Neuroimmunol 2009, 209(1-2):16-25.

19. DiPatre PL, Gelman BB: Microglial cell activation in aging and Alzheimer disease: partial linkage with neurofibrillary tangle burden in the hippocampus. J Neuropathol Exp Neurol 1997, 56(2):143-149.

20. Wyss-Coray T, Yan F, Lin AH, Lambris JD, Alexander JJ, Quigg RJ, Masliah E: Prominent neurodegeneration and increased plaque formation in complement-inhibited Alzheimer's mice. Proc Natl Acad Sci USA 2002, 99(16):10837-10842.

21. Maier M, Peng Y, Jiang L, Seabrook TJ, Carroll MC, Lemere CA: Complement C3 deficiency leads to accelerated amyloid beta plaque deposition and neurodegeneration and modulation of the microglia/macrophage phenotype in amyloid precursor protein transgenic mice. J Neurosci 2008, 28(25):6333-6341.

22. Tegla CA, Cudrici C, Trippe R 3rd, Rus V, Niculescu F, Rus H: Membrane attack by complement: the assembly and biology of terminal complement complexes. Immunol Res 2011, 51(1):45-60.

23. Xiong ZQ, Qian W, Suzuki K, McNamara JO: Formation of complement membrane attack complex in mammalian cerebral cortex evokes seizures and neurodegeneration. J Neurosci 2003, 23(3):955-960.

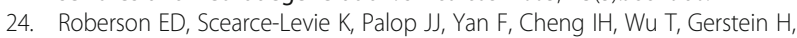
Yu GQ, Mucke L: Reducing endogenous tau ameliorates amyloid $\beta$ induced deficits in an Alzheimer's disease mouse model. Science 2007, 316(5825):750-754.

25. Lambert JC, Heath S, Even G, Campion D, Sleegers K, Hiltunen M, Combarros O, Zelenika D, Bullido MJ, Tavernier B, Letenneur L, Bettens K Berr C, Pasquier F, Fiévet N, Barberger-Gateau P, Engelborghs S, De Deyn P, Mateo I, Franck A, Helisalmi S, Porcellini E, Hanon O, The European Alzheimer's Disease Initiative Investigators, de Pancorbo MM, Lendon C, Dufouil C, Jaillard C, Leveillard T, Alvarez V: Genome-wide association study identifies variants at CLU and CR1 associated with Alzheimer's disease. Nat Genet 2009, 41(10):1094-1099.

doi:10.1186/1742-2094-9-220

Cite this article as: Britschgi et al:: Deficiency of terminal complement pathway inhibitor promotes neuronal tau pathology and degeneration in mice. Journal of Neuroinflammation 2012 9:220.

\section{Submit your next manuscript to BioMed Central and take full advantage of:}

- Convenient online submission

- Thorough peer review

- No space constraints or color figure charges

- Immediate publication on acceptance

- Inclusion in PubMed, CAS, Scopus and Google Scholar

- Research which is freely available for redistribution 